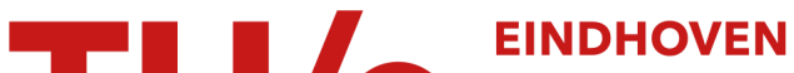 UNIVERSITY OF TECHNOLOGY
}

\section{Thermoresponsive scattering coating for smart white LEDs}

Citation for published version (APA):

Bauer, J., Verbunt, P. P. C., Lin, W. Y., Han, Y., Van, M. P., Cornelissen, H. J., Yu, J. J. H., Bastiaansen, C. W. M., \& Broer, D. J. (2014). Thermoresponsive scattering coating for smart white LEDs. Optics Express, 22(25), A1868-A1879. https://doi.org/10.1364/OE.22.0A1868

DOI:

10.1364/OE.22.0A1868

Document status and date:

Published: 01/01/2014

\section{Document Version:}

Publisher's PDF, also known as Version of Record (includes final page, issue and volume numbers)

\section{Please check the document version of this publication:}

- A submitted manuscript is the version of the article upon submission and before peer-review. There can be important differences between the submitted version and the official published version of record. People interested in the research are advised to contact the author for the final version of the publication, or visit the $\mathrm{DOI}$ to the publisher's website.

- The final author version and the galley proof are versions of the publication after peer review.

- The final published version features the final layout of the paper including the volume, issue and page numbers.

Link to publication

\section{General rights}

Copyright and moral rights for the publications made accessible in the public portal are retained by the authors and/or other copyright owners and it is a condition of accessing publications that users recognise and abide by the legal requirements associated with these rights.

- Users may download and print one copy of any publication from the public portal for the purpose of private study or research.

- You may not further distribute the material or use it for any profit-making activity or commercial gain

- You may freely distribute the URL identifying the publication in the public portal.

If the publication is distributed under the terms of Article $25 f a$ of the Dutch Copyright Act, indicated by the "Taverne" license above, please follow below link for the End User Agreement:

www.tue.nl/taverne

Take down policy

If you believe that this document breaches copyright please contact us at:

openaccess@tue.nl

providing details and we will investigate your claim. 


\title{
Thermoresponsive scattering coating for smart white LEDs
}

\author{
Jurica Bauer, ${ }^{1}$ Paul P. C. Verbunt, ${ }^{1}$ Wan-Yu Lin, ${ }^{1}$ Yang Han, ${ }^{1}$ My-Phung Van, ${ }^{1}$ \\ Hugo J. Cornelissen, ${ }^{2}$ Joan J. H. Yu, ${ }^{2}$ Cees W. M. Bastiaansen, ${ }^{3}$ and Dirk J. Broer ${ }^{1, *}$ \\ ${ }^{I}$ Department of Chemical Engineering and Chemistry, Eindhoven University of Technology, P. O. Box 513, Helix, \\ Eindhoven, $5600 \mathrm{MB}$, Netherlands \\ ${ }^{2}$ Philips Research, High Tech Campus 4, 5656 AE Eindhoven, Netherlands \\ ${ }^{3}$ School of Engineering and Material Science, Queen Mary University of London, London E1 4NS, UK \\ *d.broer@tue.nl
}

\begin{abstract}
White light emitting diode (LED) systems, capable of lowering the color temperature of emitted light on dimming, have been reported in the literature. These systems all use multiple color LEDs and complex control circuitry. Here we present a novel responsive lighting system based on a single white light emitting LED and a thermoresponsive scattering coating. The coated LED automatically emits light of lower correlated color temperature (CCT) when the power is reduced. We also present results on the use of multiple phosphors in the white light LED allowing for the emission of warm white light in the range between $2900 \mathrm{~K}$ and $4150 \mathrm{~K}$, and with a chromaticity complying with the ANSI standards (C78.377). This responsive warm white light LED-system with close-to-ideal emission characteristics is highly interesting for the lighting industry.
\end{abstract}

C2014 Optical Society of America

OCIS codes: (160.3710) Liquid crystals; (160.6840) Thermo-optical materials; (290.5850) Scattering, particles; (310.6860) Thin films, optical properties; (310.6845) Thin film devices and applications.

\section{References and links}

1. N. Zheludev, "The life and times of the LED - a 100-year history," Nat. Photonics 1(4), 189-192 (2007).

2. M.-H. Chang, D. Das, P. V. Varde, and M. Pecht, "Light emitting diodes reliability review," Microelectron. Reliab. 52(5), 762-782 (2012).

3. S. Pimputkar, J. S. Speck, S. P. DenBaars, and S. Nakamura, "Prospects for LED lighting," Nat. Photonics 3(4), 180-182 (2009).

4. E. F. Schubert and J. K. Kim, "Solid-state light sources getting smart," Science 308(5726), 1274-1278 (2005).

5. P. R. Rahm and W. R. McGrath, "Apparatus and method for adjusting the color temperature of white semiconduct or light emitters," US patent No. 6636003 B2, 2003.

6. Y. Okumura, "Color temperature-regulable led light," European Patent No. EP1462711 A1, 2004.

7. P. F. Smet, A. B. Parmentier, and D. Poelman, "Selecting conversion phosphors for white light-emitting diodes," J. Electrochem. Soc. 158(6), R37-R54 (2011).

8. L. Chen, C.-C. Lin, C.-W. Yeh, and R.-S. Liu, "Light converting inorganic phosphors for white light-emitting diodes," Materials 3(3), 2172-2195 (2010).

9. T. van Bommel and R. A. M. Hikmet, "Lighting device with thermally variable reflecting element," US patent No. 8432500 B2, 2013.

10. G. W. Gray, Fundamentals, Vol. 1 of Handbook of Liquid Crystals (Wiley-VCH, 1998).

11. P. G. de Gennes and J. Prost, The Physics of Liquid Crystals (Clarendon, 2008).

12. C. Tschierske, "Non-conventional liquid crystals-the importance of micro-segregation for self-organisation," J. Mater. Chem. 8(7), 1485-1508 (1998).

13. M. Bahadur, A. W. Norris, A. Zarisfi, J. S. Alger, and C. C. Windiate, "Silicone materials for LED packaging," Proc. SPIE 6337, 63370F (2006).

14. J. V. DeGroot, Jr., A. Norris, S. O. Glover, and T. V. Clapp, "Highly transparent silicone materials," Proc. SPIE 5517, 116-123 (2004).

15. H.-H. Moretto, M. Schulze, and G. Wagner, Silicones, Vol. 32 of Ullmann's Encyclopedia of Industrial Chemistry (Wiley-VCH, 2000).

16. X. Fu and X. Luo, "Can thermocouple measure surface temperature of LED module accurately?" Int. J. Heat Mass Transfer 65, 199-202 (2013).

17. W. J. Hwang, T. H. Lee, L. Kim, and M. W. Shin, "Determination of junction temperature and thermal resistance in the GaN-based LEDs using direct temperature measurement," Phys. Stat. Solidi C 1(10), 2429-2432 (2004). 
18. F. Schneider, J. Draheim, R. Kamberger, and U. Wallrabe, "Process and material properties of polydimethylsiloxane (PDMS) for optical MEMS,” Sens. Actuators A Phys. 151(2), 95-99 (2009).

19. Specifications for the Chromaticity of Solid State Lighting Products, ANSI Standard ANSLG C78.377-2011.

20. D. L. MacAdam, "The distribution of color matchings around a color center," J. Opt. Soc. Am. 32(1), 247-274 (1942).

21. D. Lacey, H. N. Beattie, G. R. Mitchell, and J. A. Pople, "Orientation effects in monodomain nematic liquid crystalline polysiloxane elastomers,” J. Mater. Chem. 8(1), 53-60 (1998).

22. B. Marciniec and J. Matisons, Hydrosilylation: A Comprehensive Review on Recent Advances, Vol. 1 of Advances in Silicon Science (Springer, 2009).

\section{Introduction}

Driven by advances in R\&D in the field of light-emitting diodes (LEDs) [1-3], the lighting industry is expected to shift towards intelligent lighting systems in the coming years [4]. Controlling lighting by external stimuli such as temperature or electrical current is paramount for the development of these smart systems. An often experienced shortcoming of LEDs is the deviation of the emitted light spectrum from that of candescent lamps, e.g. being perceived as warm when dimmed and more neutral at higher intensities. In this paper we present a thermoresponsive coating that, when applied on an LED, mimics the intensitydependent behavior of a candescent lamp. The intensity-related heat generated by white-light LEDs controls the correlated color temperature (CCT) of the LED-emitted light.

Addressing the CCT of emitted light, for instance switching between warm white and cold white light has attracted much attention. In order to achieve this switching, most systems use multiple LEDs $[5,6]$. The main disadvantage of such devices, however, is the need for a control system necessary for addressing all the LEDs separately. The concept of a smart single white light LED, on the other hand, is more appealing as this system would not require such a control system. A white light emitting LED package contains a blue light emitting LED embedded in a matrix material containing a photoluminescent material (with the lighting nomenclature addressed as the phosphor). The phosphor converts a part of the blue light to light of another color $[2,3,7,8]$. The CCT of the light emitted by the LED package depends on the type of blue LED and the type and quantity of phosphor in the package. As depicted in Fig. 1, a scattering coating on top of such an LED package facilitates more of the aforementioned light conversion from blue to another color by redirecting the emitted light back to the phosphor where it can be absorbed and subsequently re-emitted at another wavelength [9]. If the applied coating can be switched between a scattering and a transparent state, the CCT of the emitted light can be addressed [Fig. 1].

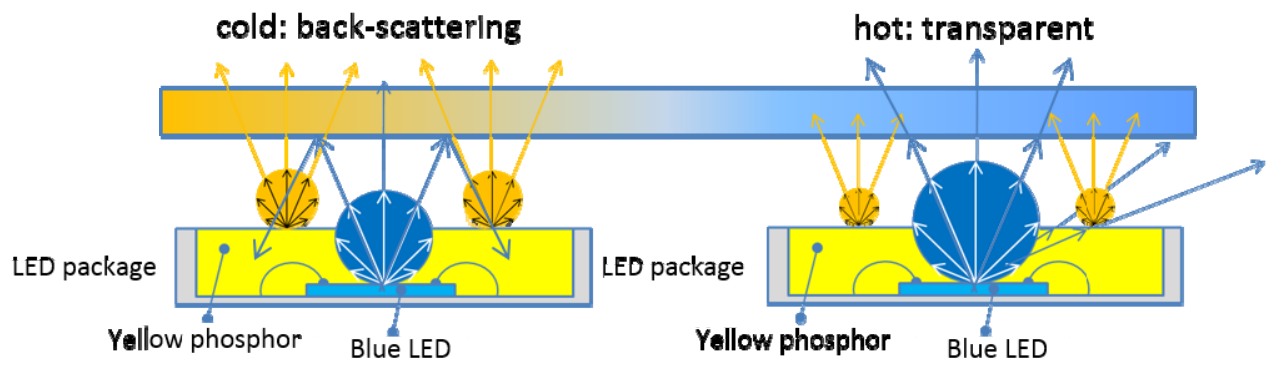

Fig. 1. Schematic depiction of the LED-package with the thermo-responsive coating on top. The picture on the left shows the device at low temperature/current, where the coating is in a scattering state. In the picture on the right the current/temperature is high and the coating is thus transparent. The color of the coating in this schematic depiction shows the color of the light leaving the device. For the sake of clarity the coating is depicted out of contact with the LED package; it should be noted, however, that the coating is brought into optical and thermal contact with the LED package. 


\section{Results and discussion}

Non-aligned smectic liquid crystalline materials are known to be scattering, and when heated above their transition temperature to the isotropic state these materials become transparent $[10,11]$. This makes liquid crystalline materials ideal candidates for a thermoresponsive scattering coating [9]. Due to their appealing properties we have chosen to explore siloxane based liquid crystals [12]. Siloxanes are well-known to be temperature stable which is highly desirable during continuous LED operation at elevated temperature as well as in the curing step at elevated temperature during the coating procedure $[13,14]$. Moreover, due to the siloxanes' flexible main chain these materials tend to show fast response on temperature changes [15]. In order to devise a smart coated LED a liquid crystalline compound was designed with the clearing temperature matching the surface temperature of an operational LED $[16,17]$. The exact chemical structure and the preparation of the siloxane compound are described in the appendix (Fig. 7). The optical properties of the coating as well as the CCT of the light emitted by a coated LED can then be tuned by addressing the electrical current powering the LED.

Differential Scanning Calorimetry (DSC) measurements of the siloxane compound in the temperature range from -50 to $150{ }^{\circ} \mathrm{C}$ show a total of four phases with the corresponding transitions at $-14,14$ and $48{ }^{\circ} \mathrm{C}$ (Fig. 7 in the appendix). Aided by Polarization Optical Microscopy (POM) and Small-Angle X-Ray Scattering (SAXS) measurements (Figs. 7 and 8 in the appendix, respectively) the phases have been identified as a glassy state, smectic C, smectic A and the isotropic phase from low to high temperature. For the aforementioned application in lighting we would like to exploit the transition between the scattering smectic A phase and the transparent isotropic state at $48^{\circ} \mathrm{C}$.

In the temperature range of interest to the application, the material is either liquid crystalline or in the liquid state which makes the material sticky and pliable. With the goal of making a more mechanically robust coating the siloxane compound was mixed with ethoxylated bisphenol A diacrylate (BPADA), which can be photopolymerized after application on the LED. The refractive index of BPADA, as reported by the supplier, is similar to the assumed refractive index of compound $\mathbf{3}$ in the isotropic phase [18] causing the coating to appear transparent when the siloxane compound is in the isotropic phase and scattering when in the smectic phase. A photopolymerized mixture of the siloxane and BPADA in a 1:2 weight ratio was examined by Scanning Electron Microscopy (SEM) revealing domains of the siloxane with an average size of $120 \mathrm{~nm}$ in a matrix of BPADA. The experimental details and the SEM images are available in the appendix [Fig. 9].

The coating was applied to a cold white light emitting LED and the CCT of the emitted light was measured at different currents. The results are displayed in Fig. 2(a). 


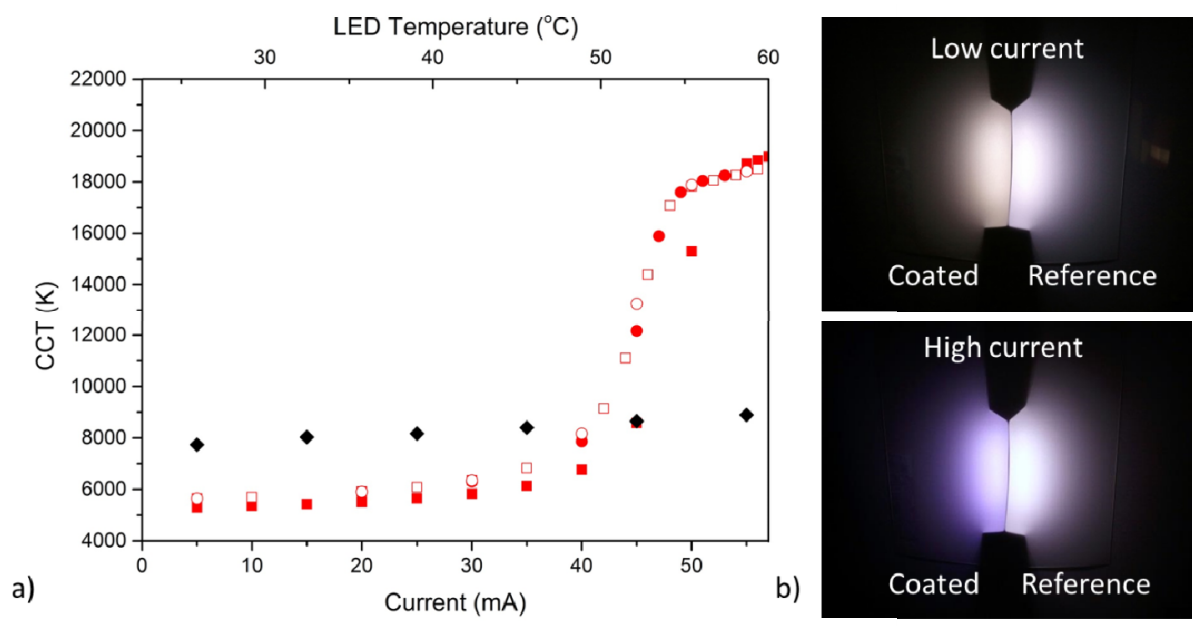

Fig. 2. a) Correlated color temperature (CCT) of the light emitted by the LED at different currents and temperatures applied to a cold white light LED coated with the thermo-responsive coating. The black diamond symbols show the uncoated LEDs. The red squares display the first run of increasing (closed symbols) and decreasing (open symbols) the current. The red circles display the second run. b) Demonstrator consisting of a row of coated cold white LEDs on the left-hand side and a row of bare cold white LEDs on the right-hand side. The top picture shows the demonstrator operating at a low current $(\sim 20 \mathrm{~mA} / \mathrm{LED})$ and the bottom picture at a high current $(\sim 60 \mathrm{~mA} / \mathrm{LED})$. In order to capture the switching of CCT on camera a diffuser is placed on top of the demonstrator at a large distance (approximately $5 \mathrm{~cm}$ ).

As can be seen in Fig. 2(a), the CCT remains relatively constant at approximately $5500 \mathrm{~K}$ in the current range $0-35 \mathrm{~mA}$. Around $45 \mathrm{~mA}$ the CCT increases rapidly with current to reach approximately $20000 \mathrm{~K}$. In order to clarify the results described in Fig. 2(a), the temperature of the LED surface was measured at different currents (see the appendix for the experimental details and Fig. 10 for the correlation between the applied current and the surface temperature of the LED) and is displayed in Fig. 2(a). The transition of the CCT from approximately 5500 $\mathrm{K}$ to $20000 \mathrm{~K}$ occurs when the surface of the LED reaches $50-55^{\circ} \mathrm{C}$, which is just above the clearing temperature of the liquid crystalline material. This indicates that the change in CCT is caused by the transition of the coating from a scattering to a transparent state. As anticipated in the presence of a scattering coating [Fig. 1], at low currents the CCT of the light emitted by a coated LED is lower than that for a bare LED [Fig. 2(a)]. At higher currents, however, the CCT of the light emitted by a coated LED is observed to be significantly higher than that for a bare LED, as evident from Fig. 2(a). This can be explained by the fact that the coating is in optical contact with the LED package. Without the coating, a part of the light is reflected back into the LED package, increasing the path length of blue LED-emitted light through the phosphor and effectively increasing the chance for absorption by the phosphor. When the coating is applied, it will cause outcoupling of the light from the LED-package and thereby reducing the path length of the blue LED-emitted light through the phosphor.

In order to show the effect of the coating on the light emitted by the LEDs a demonstrator was built on a circuit board comprising a row of coated cold white LEDs on one side and a row of bare cold white LEDs on the other side. Figure 2(b) shows the demonstrator at a low current ( $\sim 20 \mathrm{~mA} / \mathrm{LED}$, top picture) and at a high current ( $\sim 60 \mathrm{~mA} / \mathrm{LED}$, bottom picture). Since the intensity of the light was too high for the photocamera to capture the effect of the coating a diffuser was placed on top of the demonstrator at a large enough distance not to affect the CCT. In the pictures it can be clearly seen that the CCT of the light emitted by the bare LEDs is approximately the same at both currents, while the row of coated LEDs emits a more blueish light at high current and a more yellow light at a low current. These pictures support the results from the CCT measurement. 
The resulting LED system emits light of CCT tunable in the range from $5500 \mathrm{~K}$ to 20000 K. Lighting applications mostly feature LEDs emitting white light with a CCT between 2700 $\mathrm{K}$ and $5000 \mathrm{~K}$, even though the American National Standards Institute's (ANSI) standards for LEDs [19] describe systems up to $6500 \mathrm{~K}$. Another requirement for white light LEDs, described in the same ANSI standard, is the tolerance in chromaticity with respect to black body emitters. These defined tolerances can be approximated by 7 -steps MacAdam ellipses [20] around the black body line in CIE color space.

White light LEDs consisting of a blue LED and a single phosphor [7-9] emit light of chromaticity along the line in the CIE color space diagram connecting the chromaticity of the blue LED to that of the phosphor. For the cold white light LEDs this is shown in Fig. 3. The purple line connects the chromaticities of the blue LED and the yellow phosphor in question, the data points (at different currents) corresponding to uncoated LEDs are depicted in black and the data points (at different currents) corresponding to the coated LEDs are shown in blue. The data points from both the coated and the uncoated LEDs are found on the purple chromaticity line for this type of LED. Figure 3 also displays the 5-steps MacAdam ellipses around the black body line (curve shown in black). The MacAdam ellipses show the tolerance in chromaticity of the smart LED with respect to the standards in the LED industry [19]. The chromaticity of the coated cold white light LED complies with the standards at low current (and thus low CCT) but significantly deviates from the black body line at high current (and thus high CCT). Due to the limited overlap between the chromaticity line of the cold white light LED and the black body line as well as due to the operation in the CCT range between $5500 \mathrm{~K}$ and $20000 \mathrm{~K}$, a white light LED design of different properties should be used in order to obtain a responsive LED system that meets the ANSI requirements.
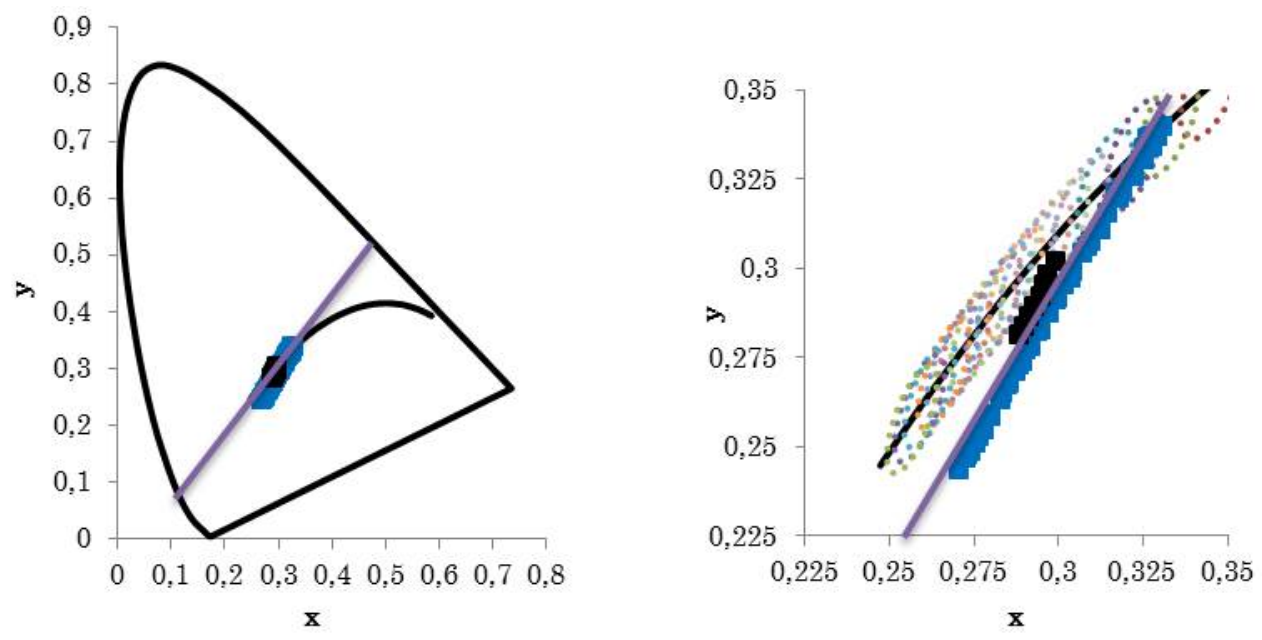

Fig. 3. The CIE 1931 diagram depicting the chromaticities of the light emitted by an uncoated cold white light LED (black data points) and a coated cold white light LED (blue data points), measured at different currents $(5-60 \mathrm{~mA})$. The right figure is an expansion of the relevant part of the left figure. The purple line represents the connection between the value in color space of the blue LED and the phosphor in question. The black curve represents the ideal black body emitter. The ellipses depict 5-steps MacAdam ellipses around black body emitters at a certain temperature.

As can be seen in Fig. 3, the black body line is not represented by a straight line in the range between $2700 \mathrm{~K}$ and $5000 \mathrm{~K}$ in the color space. A consequence of this is that the chromaticity line connecting the chromaticity points of the blue LED and a single phosphor, both comprising a white light LED, will display only limited overlap with the curved black body line. In order to achieve greater overlap between the black body line and the chromaticity line of the LED, the LED chromaticity line should display a certain curvature as well. To this end we opted for the use of multiple phosphors in one LED package with one 
phosphor absorbing only the light emitted by the blue LED and the other phosphor absorbing both the light emitted by the blue LED and the light emitted by the first phosphor. The absorption and emission spectra of the components of such an LED are depicted in Fig. 4.

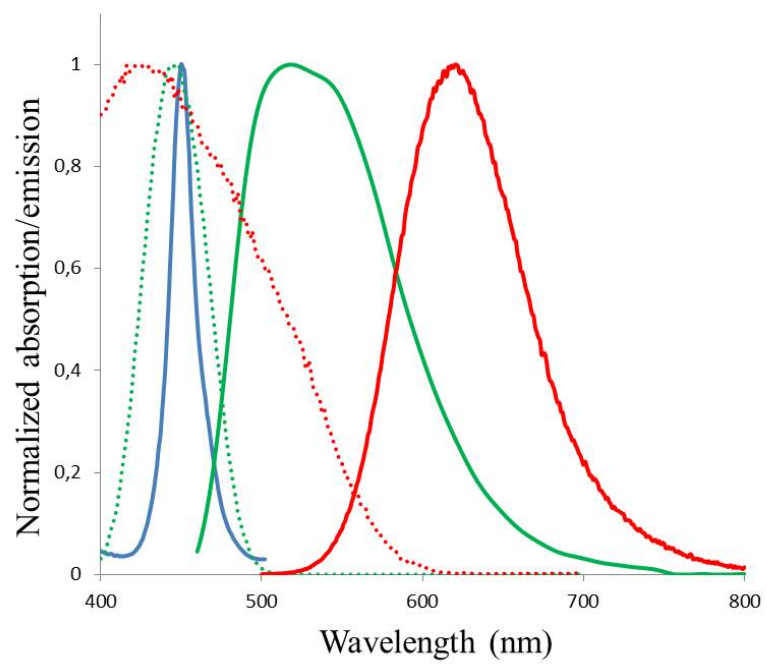

Fig. 4. Absorption (dashed lines) and emission (solid lines) spectra of the yellow (green lines) and the red phosphor (red lines) and the blue LED (blue line) present in a warm white light LED.

The thermoresponsive coating was applied to a warm white light LED (the LED package comprises two phosphors and a blue LED and their absorption and emission spectra can be seen in Fig. 4). The CCT and the chromaticity values of the light emitted by the coated and uncoated LEDs were measured at different electrical currents [Fig. 5(a)]. The CCT of the light emitted by the uncoated LED was measured to be approximately $3200 \mathrm{~K}$ (black symbols in Fig. 5(a)) and was found to be independent of the current applied (5-70 mA). At low current $(5 \mathrm{~mA})$ the CCT of the light emitted by a coated LED was measured to be around $2900 \mathrm{~K}$ and increased with current (red symbols in Fig. 5(a)). At currents exceeding $75 \mathrm{~mA}$ the CCT becomes constant at approximately $4150 \mathrm{~K}$. Multiple cycles of increasing and decreasing current were carried out with hardly any fatigue [Fig. 5(a)]. This behavior is in agreement with measurements on the coated cold white light LEDs. 


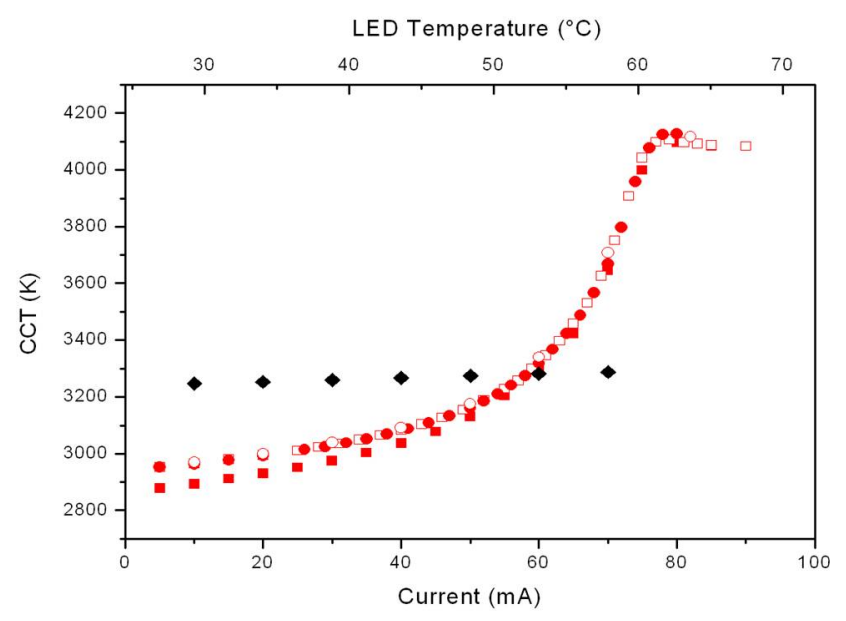

a)

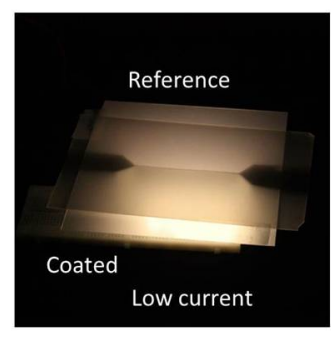

b)

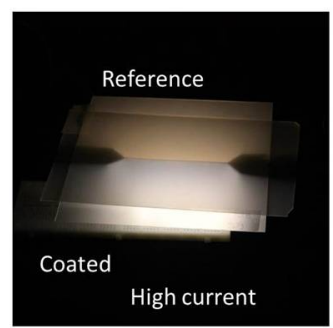

Fig. 5. a) Correlated color temperature (CCT) of the light emitted by the LEDs at different currents and temperatures. The black symbols display the uncoated LED and the red symbols the coated LED. The red squares depict the first run of increasing (closed symbols) and decreasing (open symbols) the current. The circles display the second run. b) Demonstrator consisting of a row of coated warm white LEDs (bottom) and a row of bare warm white LEDs (top). The top picture shows the demonstrator operating at a low current $(\sim 20 \mathrm{~mA} / \mathrm{LED})$ and the bottom picture at a high current ( $\sim 80 \mathrm{~mA} / \mathrm{LED})$. In order to capture the switching of CCT on camera a diffuser is placed on top of the demonstrator at a large distance (approximately 5 $\mathrm{cm})$.

In order to show the effect of the coating on the light emitted by the warm LEDs a demonstrator was built on a circuit board comprising a row of coated cold white LEDs on one side and a row of bare cold white LEDs on the other side. Figure 5(b) shows the demonstrator at a low current $(\sim 20 \mathrm{~mA} / \mathrm{LED}$, top picture) and at a high current $(\sim 80 \mathrm{~mA} / \mathrm{LED}$, bottom picture). The pictures show that the CCT of the light emitted by the bare LEDs is approximately the same at both currents, while the row of coated LEDs emits a more blueish light at high current and a more yellow light at a low current. The changes in the light upon changing the current are more subtle that in the case of cold white LEDs [Fig. 2(b)]. These pictures [Fig. 5(b)] support the results from the CCT measurement.

The chromaticities of the coated (blue symbols) and the uncoated (black symbols) LED systems were measured as well and the results are displayed in Fig. 6 along with the 5-steps MacAdam ellipses around the black body line. The presence of two phosphors in the LED package positions the chromaticity line between the separate lines connecting the chromaticities of the blue LED and each phosphor separately. Figure 4 shows that the red phosphor not only absorbs the blue LED light but the light emitted by the yellow phosphor as well which in turn causes the resultant chromaticity line to deviate from linearity as it comes closer to the chromaticity line connecting the chromaticities of the blue LED and the red phosphor [Fig. 6]. This deviation from linearity also keeps the chromaticity of the coated LED light within 5-steps MacAdam ellipses from the black body line at all currents. This means that the investigated LED system obeys ANSI standards at all operational currents which is a prerequisite for any real-life applications [19]. Various samples of coated warm white LEDs were prepared (the relative amount of compound $\mathbf{3}$ and the polymerization temperature of the coating were varied) and the emitted light was analyzed in color space for different electrical currents (Fig. 11 in the appendix). Although the color temperature ranges differed slightly from sample to sample, all corresponding chromaticities followed the black body line within the 5-steps MacAdam ellipses at all measured currents. 

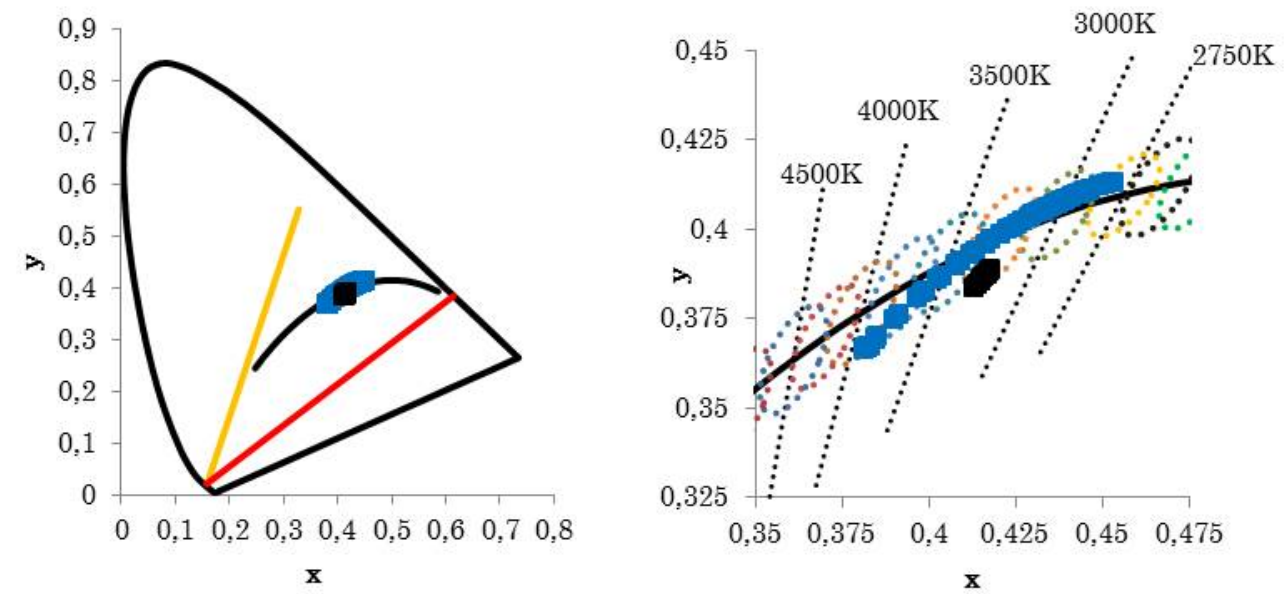

Fig. 6. CIE 1931 diagram depicting the chromaticities of the light emitted by an uncoated (black) and a coated LED (blue), measured at different currents $(5-90 \mathrm{~mA})$. The right figure is an expansion of the relevant part of the left figure. The red and yellow lines represent the connections between the chromaticity of the blue LED and the two different phosphors. The black curve represents the ideal black body emitter. The ellipses depict 5-steps MacAdam ellipses around black body emitters at a certain temperature. Several CCT lines are shown as black dotted lines.

\section{Conclusion}

In this paper we present a novel smart LED system, based on single white emitting LEDs, able to adjust the CCT of the emitted light in response to electrical current. The smart LEDs are based on a thermoresponsive material, coated on top of LEDs, that uses the heat generated by the LED to switch between a scattering and a transparent state, in turn causing a change in the CCT of the light emitted by the device. Furthermore, by tuning the design of the LED we were able to develop an LED system that automatically changes the CCT of the emitted light in the range between 2900 and $4150 \mathrm{~K}$ upon changing the current applied to the LED. Due to the presence of two different phosphors in the LED package, the chromaticity of the light emitted by the LED system remains within the 5-steps MacAdam ellipses from the black body line at all currents and CCTs, rendering this LED system applicable in the lighting industry.

\section{Materials and experimental procedures}

LEDs: The cold and warm white light LEDs used were models NSSW156 and NSSW157 from the company Nichia, respectively.

Application of the coating on top of the LED: A 50\% solution by weight of a 1:2 mixture by weight of compound $\mathbf{3}$ and ethoxylated bisphenol A diacrylate (Sigma-Aldrich) containing 1\% Irgacure 184 (Ciba Specialty Chemicals) as photoinitiator in toluene was stirred at room temperature for 3 hours. A total of $2 \mu 1$ of this mixture was dropcast on top of an LED with a concave top surface. The coated LED was dried in air overnight to allow the solvent to evaporate and then the LED was stored in a nitrogen atmosphere at $60{ }^{\circ} \mathrm{C}$ for 10 minutes prior to photopolymerization for 10 minutes.

CCT measurements: The CCT and the chromaticities of the emitted light at different currents was measured using a Konica Minolta CL500A spectrometer in a confined black space. The current was applied using a Keithley SMU2400 power source. 


\section{Appendix}

Preparation and chemical characterization of the siloxane compound 3

The synthetic precursor 2 was prepared following a literature procedure [21] and coupled with 1 in a Pt-catalyzed hydrosilylation [22] reaction to afford the desired block co-polymer 3 (Fig. 7).

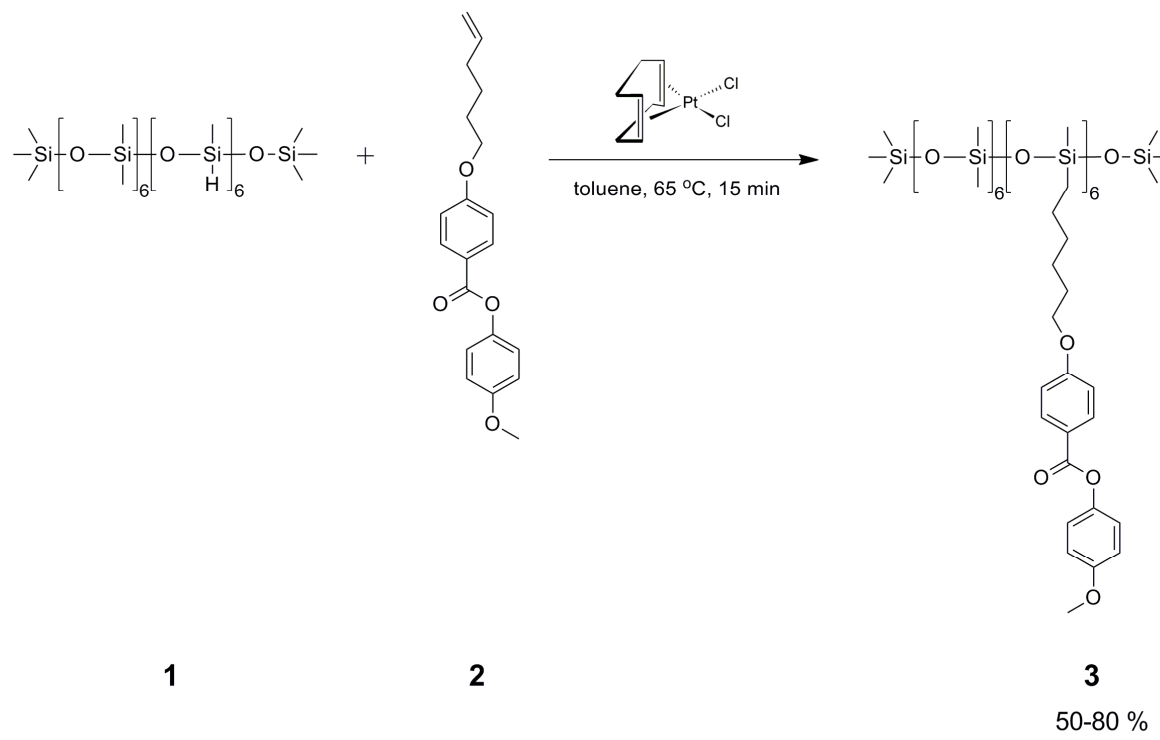

Fig. 7. Synthesis of 6-(4-((4-methoxyphenoxy)carbonyl)phenoxy)hexyl-methylsiloxane dimethylsiloxane copolymer (compound $\mathbf{3}$ ).

6-(4-((4-methoxyphenoxy)carbonyl)phenoxy)hexyl-methylsiloxane dimethylsiloxane copolymer(compound 3): Compound $2(250 \mathrm{mg}, 0.78 \mathrm{mmol})$ and dichloro(1,5cyclooctadiene)platinum(II) (catalytic amount; on the tip of the spatula, Sigma-Aldrich) were mixed at room temperature and under an argon atmosphere and dissolved in dry toluene with stirring. Siloxane 1 (105 $\mu 1,0.11 \mathrm{mmol}$, Sigma-Aldrich), was added in one portion and the mixture was stirred at room temperature for $10 \mathrm{~min}$ and then heated to $65{ }^{\circ} \mathrm{C}$ (oil bath temperature). The reaction could be followed by ${ }^{1} \mathrm{H}-\mathrm{NMR}$ or IR and was typically completed within 15 minutes. The solvent was evaporated and the residue was thoroughly and repeatedly rinsed with methanol. Alternatively, the residue after evaporation can be dissolved in a minimum amount of toluene and then precipitated by the addition of methanol. These procedures were repeated until there was no residual monomeric species observed by NMR. The crude product was obtained as a grey to black viscous liquid and was further purified by repeated filtrations over a plug of silica using toluene and ethyl acetate in different ratios to flush the silica. The product is obtained as a white viscous liquid at room temperature (206 mg, 63\%). ${ }^{1} \mathrm{H}$ NMR (400 MHz, $\mathrm{CDCl}_{3}$ ): $\delta / \mathrm{ppm}: 8.09$ (br, 12), 7.08 (br, 12), 6.90 (br, 24), 3.98 (br, 12), 3.80 (br, 18), 1.79 (br, 12), 1.40 (br, 36), 0.55 (br, 12), 0.09 (br, 58). ${ }^{13} \mathrm{C}$ NMR (100 $\mathrm{MHz}, \mathrm{CDCl}_{3}$ ): $\delta / \mathrm{ppm}: 165.3,163.5,157.3,144.6,132.3,122.6,121.8,114.6,114.3,68.4$, $55.7,33.2,29.3,25.9,23.1,17.7,1.4,-0.1$.

\section{Physical characterization of the siloxane compound 3}

The DSC measurements were performed at a heating/cooling rate of $10{ }^{\circ} \mathrm{C} \min ^{-1}$ and the microscope images were taken between cross-polarizers (Fig. 8). 


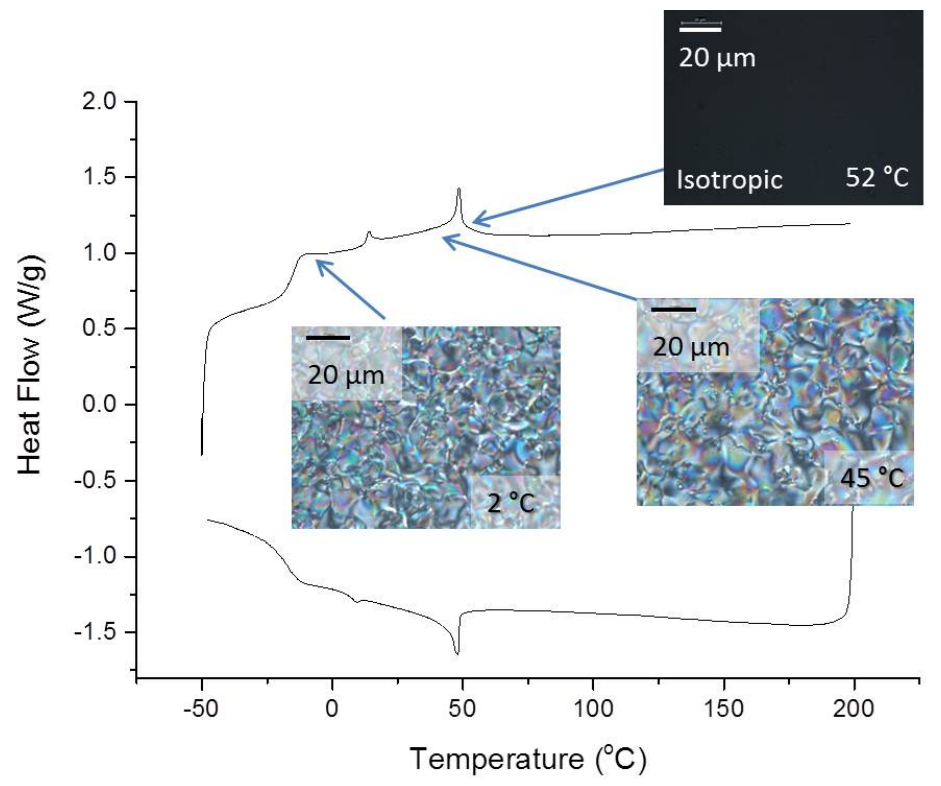

Fig. 8. The DSC and POM investigation of the phase behavior of compound 3 .

The Wide-Angle X-Ray Scattering (WAXS) and Small-Angle X-Ray Scattering (SAXS) measurements were performed on the thermo-responsive material sealed in a $1 \mathrm{~mm}$ thick glass capillary inside a custom-built heating stage equipped with a permanent magnetic field $(1 \mathrm{~T})$ needed to induce uniaxial alignment. The sample was irradiated with a $1.54 \AA$ GeniX$\mathrm{Cu}$ ultra-low divergence source. The material was heated to the isotropic phase prior to being cooled with a rate of $10{ }^{\circ} \mathrm{C} \mathrm{min}^{-1}$. Diffraction patterns were recorded upon cooling on a Pilatus 300K silicon pixel detector (Fig. 9).
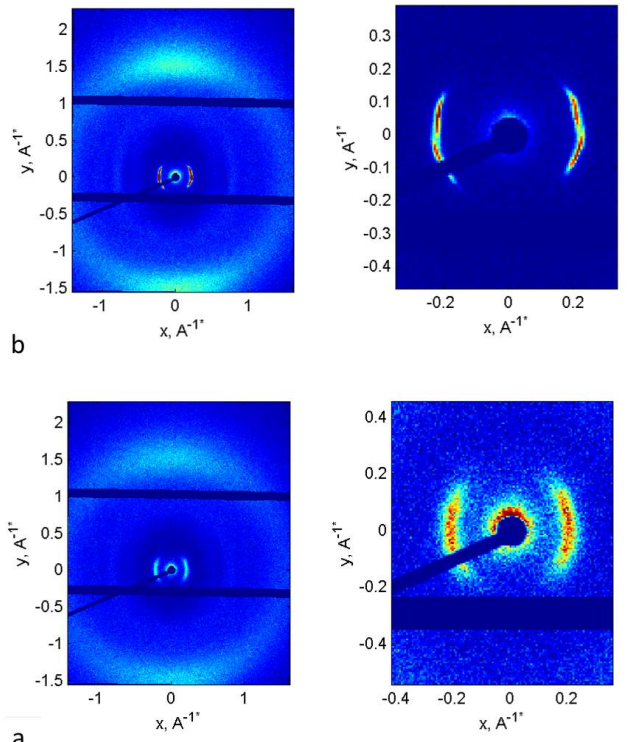

Fig. 9. The WAXS (left) and SAXS (right) images for the a) higher-temperature smectic phase and b) lower-temperature smectic phase (see Fig. 8). 


\section{Characterization of the coating}

\section{Scanning Electron Microscopy (SEM)}

In order to study the morphology of the thermo-responsive coating, Scanning Electron Microscopy (SEM) images have been made. The coating was printed on a thin $(1 \mathrm{~mm})$ glass slide and photopolymerized at $60{ }^{\circ} \mathrm{C}$ in a nitrogen atmosphere for 10 minutes; the same conditions as used for the coatings on the LEDs. The sample was cooled after polymerization, using liquid nitrogen and the sample was broken. The siloxane liquid crystal (compound $\mathbf{3}$ ) was removed by treatment with ethyl acetate and the sample was dried afterwards. The material was made conductive by sputtering gold on the sample for 30 seconds at a current of $65 \mathrm{~mA}$. SEM images were taken from the side of the coating at $5 \mathrm{keV}$ (Fig. 10).

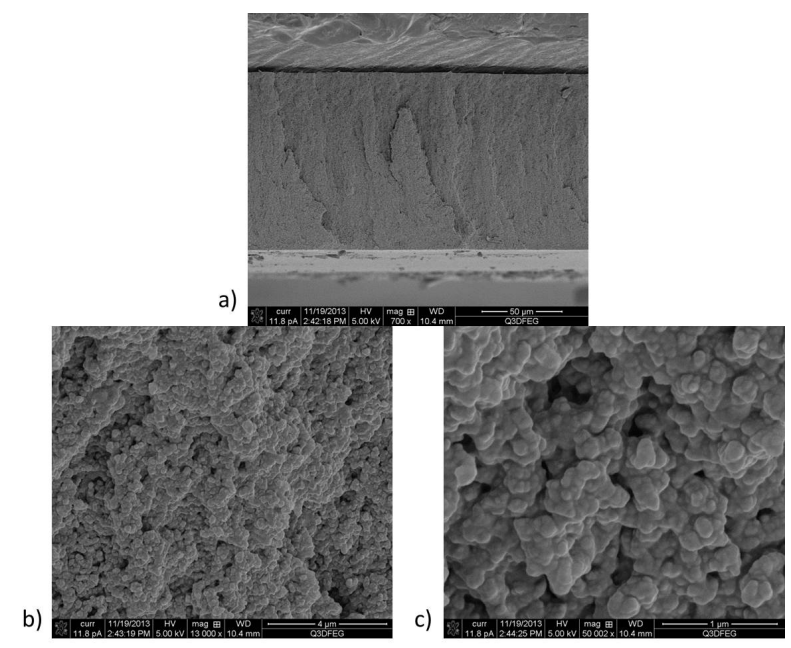

Fig. 10. SEM images of the thermoresponsive coating at different magnifications: a) 700x, b) $13000 \mathrm{x}, \mathrm{c})$ 50000x.

Thermal characterization of the cold white LED

Surface temperature of the LED

The surface temperature of the cold white LED was measured using a thermocouple, which was taped to the surface (phosphor) of the LED. The current applied to the LED was set using a Keithley SMU2400 (Fig. 11).

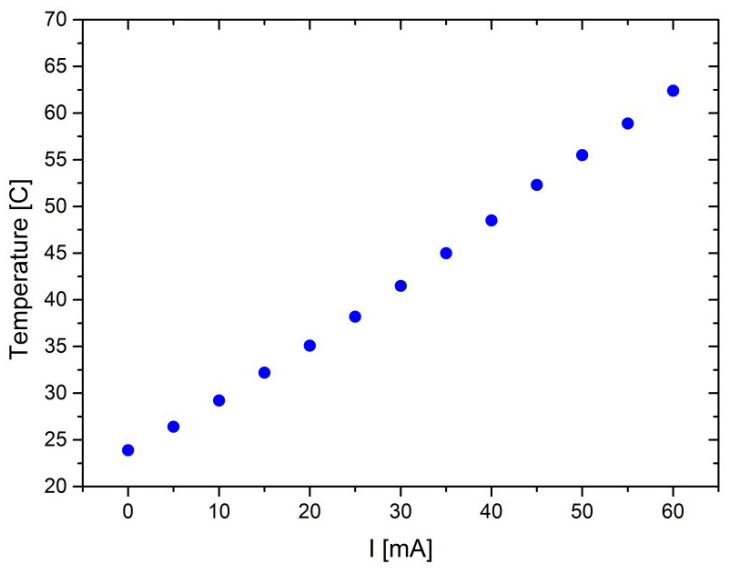

Fig. 11. Surface temperature of the LED as function of the applied current. 
Color space analysis of the light emitted by coated warm white LEDs

The light emitted by various samples of coated warm white LEDs was analyzed in color space (Fig. 12).

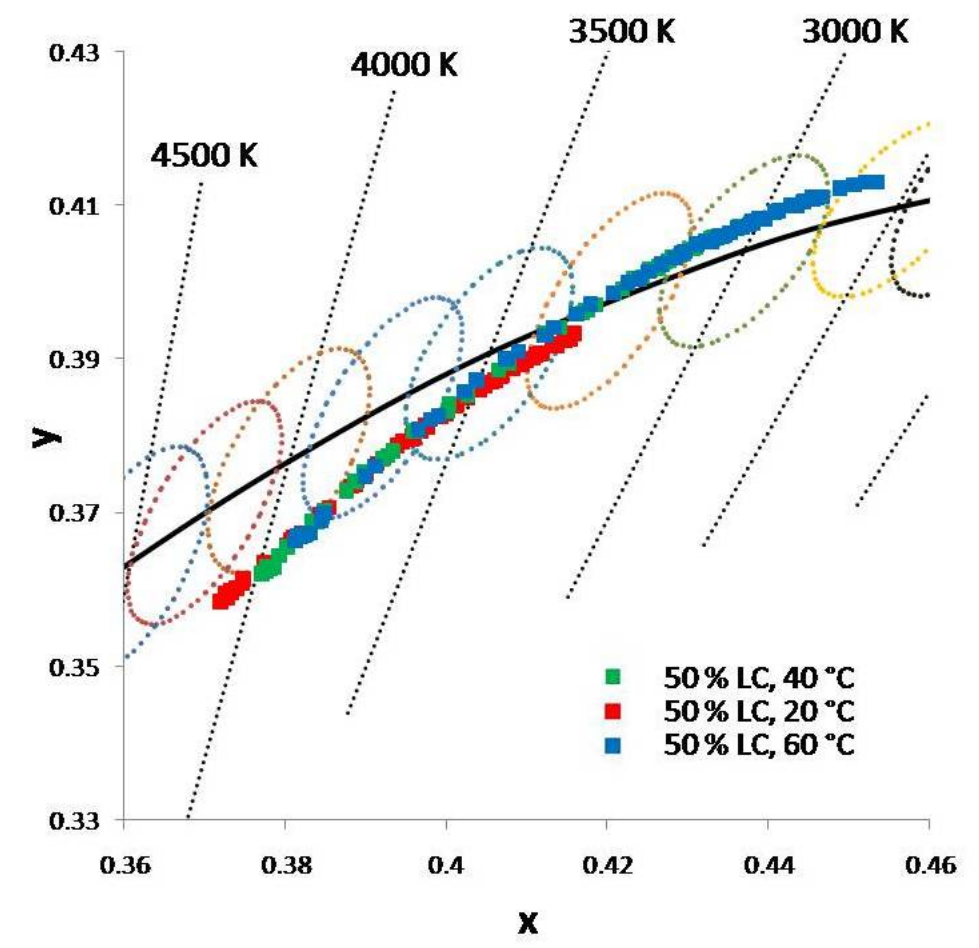

Fig. 12. CIE 1931 diagram depicting the chromaticities of the light emitted by various samples of coated warm white LEDs measured at different electrical currents $(5-60 \mathrm{~mA})$. The data points shown in different colors were obtained by polymerization at different temperatures. All coatings contained $50 \%$ of compound 3 . The black curve represents the ideal black body emitter. The ellipses depict 5-steps MacAdam ellipses around black body emitters at a certain temperature. Several CCT lines are shown as black dotted lines.

\section{Acknowledgments}

This research project has been supported by the European Commission under the 7th framework program: FP7-ICT-2011-288262. Author 1 and Author 2 contributed equally to this work. The authors would like to thank dr. I. Shishmanova for her assistance during the SEM measurements. 